\title{
Práticas Didáticas de Ensino, Pesquisa, Cultura e Extensão Universitária no Parque CienTec-USP: 0 Projeto Solo na Escola-Geografia-USP
}

\author{
Déborah de Oliveira \\ Departamento de Geografia da Faculdade de Filosofia, Letras e Ciências Humanas da Universidade de São Paulo \\ * Autora para correspondência: debolive@usp.br
}

\section{RESUMO}

Este relato apresenta o projeto intitulado Solo na Escola-Geografia-USP como parte de atividades de pesquisa, cultura e extensão universitária, voltadas a divulgar o solo e sua importância por meio de práticas não formais, e sim lúdicas e didáticas. O projeto conta com experimentos que têm como objetivo mostrar ao visitante conceitos importantes sobre o solo, como, por exemplo: sua formação, horizontes do solo, cores, magnetismo, erosão do solo, dentre outros. Alunos de graduação em Geografia e Licenciatura em Geociências e Educação Ambiental atuam no projeto como monitores com bolsa do Programa Unificado de Bolsas da USP (PUB). Recebemos mensalmente por volta de trezentos visitantes escolares e público em geral.

Palavras-Chave: Solo; Educação Não Formal; Experimentos Didáticos.

\begin{abstract}
This report presents the Soil at School-Geography-USP project as part of research activities, culture and university extension as a way to disseminate the soil and its importance through ludic and didactic activities in the scope of non-formal activities. This project has experiments that show to the visitor important concepts about the soil, such as soil formation, soil horizons, soil color, soil magnetism, soil erosion etc. Undergraduate students in Geography and Geosciences and Environmental Education act as monitors with scholarship of the Unified Program of Scholarships of USP (PUB). We receive monthly about 300 school visitors and the general public.
\end{abstract}

Keywords: Soil; Non-Formal Education; Didactic Experiments.

O solo, elemento fundamental para a manutenção da vida na Terra e recurso natural finito na escala de vida humana, tem sido esquecido e muitas vezes abandonado. Nesse sentido, o solo deve ser visto como componente essencial do meio ambiente e da vida, assim deve ser conhecido e preservado da degradação (MUGGLER et al., 2006).

Os Parâmetros Curriculares Nacionais (PCN) indicam o tema solo em séries dos ensinos fundamental e médio sempre associado às disciplinas Geografia, Ciências e Biologia, porém os professores de tais disciplinas muitas vezes não têm o preparo adequado para tratar do tema.

Depois de anos de experiência profissional na área de solos, percebeu-se, ministrando aulas de Geografia, a necessidade de se divulgar a ciência do solo e de despertar nas pessoas o interesse pelo tema (OLIVEIRA, 2014). Nesse sentido, o Projeto Solo na Escola, localizado no Parque CienTec da USP, tem o objetivo de divulgar e popularizar a ciência do solo, tanto para professores, estudantes, como para o público em geral.

O projeto nasceu no Departamento de Geografia da USP, denominado inicialmente de Grupo de Educação em Solos-Geografia-USP, com um grupo de alunos de graduação, no ano de 2009, com a perspectiva de se pesquisarem materiais didáticos passíveis de serem reproduzidos em sala de aula pelos professores que queiram tratar do tema solo. Os alunos contaram com bolsa Ensinar com Pesquisa e Aprender com Cultura e Extensão, todas oferecidas pela Pró-Reitoria de Pesquisa e Pró-Reitoria de 
Cultura e Extensão Universitária da USP, respectivamente. Hoje contamos com as bolsas do Programa Unificado de Bolsas da USP (PUB), que permitem a alunos de graduação em Geografia e Licenciatura em Geociências e Educação Ambiental atuarem no projeto como monitores.

Os alunos estudaram os Parâmetros Curriculares Nacionais para que pudessem ser preparados para atuar em cada ciclo com o tema solo, atendendo as necessidades de cada faixa etária. Jogos, oficina de tintas com solo, experimentos e livros didáticos foram elaborados nessa etapa (OLIVEIRA, 2010), contando sempre com a ajuda dos estudantes de graduação em Geografia e Licenciatura em Geociências e Educação Ambiental.

Uma lacuna estava evidente. Não tínhamos recursos nem um espaço físico para alojar nossos materiais e onde receber pessoas para visitarem e interagirem com os experimentos.

Quando o Edital 2012/2013 da Pró-Reitoria de Cultura e Extensão Universitária foi lançado, submetemos nosso projeto, que foi aprovado, e passamos a ter recursos para continuar nossos trabalhos, com a compra de equipamentos e construção de mais experimentos. Mas ainda não tí- nhamos o espaço físico para alojar tais materiais e receber visitantes.

No ano de 2013, o Parque CienTec nos ofereceu um espaço físico, onde pudemos começar a instalar nosso projeto, e inauguramos o Projeto Solo na Escola-Geografia-USP no dia 15 de abril de 2014 em comemoração ao Dia da Conservação do Solo (Figura 1).

Nesse mesmo dia recebemos a visita de estudantes de escola pública estadual (Figura 2):

Desde o início do projeto participamos de vários Simpósios Brasileiros de Educação em Solos, tanto oferecendo palestras como apresentando trabalhos orais e banners, além de participarmos do 20th World Congress of Soil Science, ocorrido na Coreia do Sul, no ano de 2014. Nesses eventos fizemos contatos com vários outros pesquisadores brasileiros e estrangeiros que trabalham com a temática, o que nos motivou a continuar.

Oferecemos cursos para reciclagem de professores dos ensinos fundamental e médio na Semana de Geografia, promovida pelo Departamento de Geografia da USP anualmente, e também na Jornada Geoensino, evento promovido pelo mesmo departamento bianualmente.

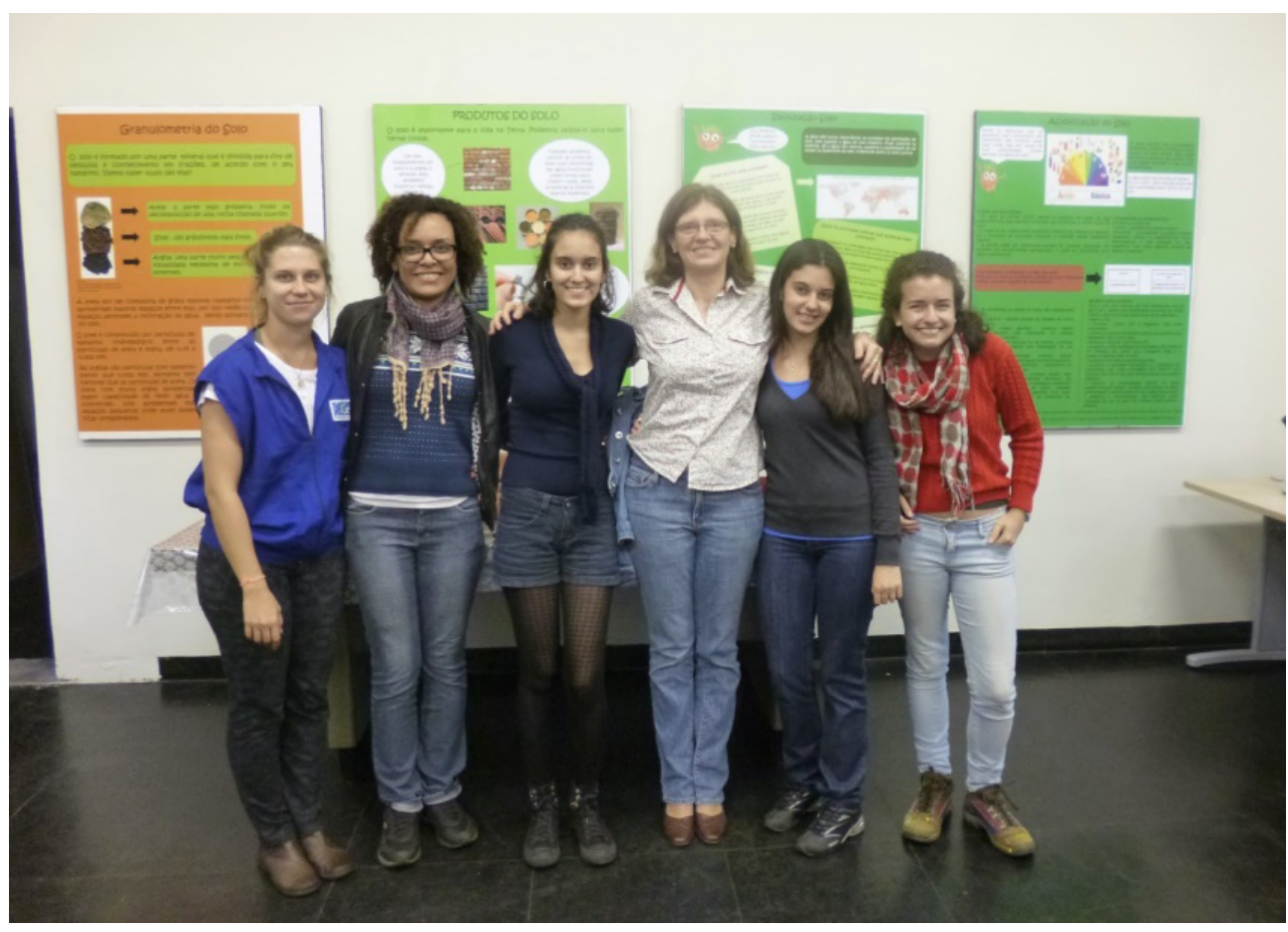

Figura 1 - Inauguração do Projeto Solo na Escola-Geografia-USP no Parque CienTec em 15/04/2014, Dia da Conservação do Solo. 


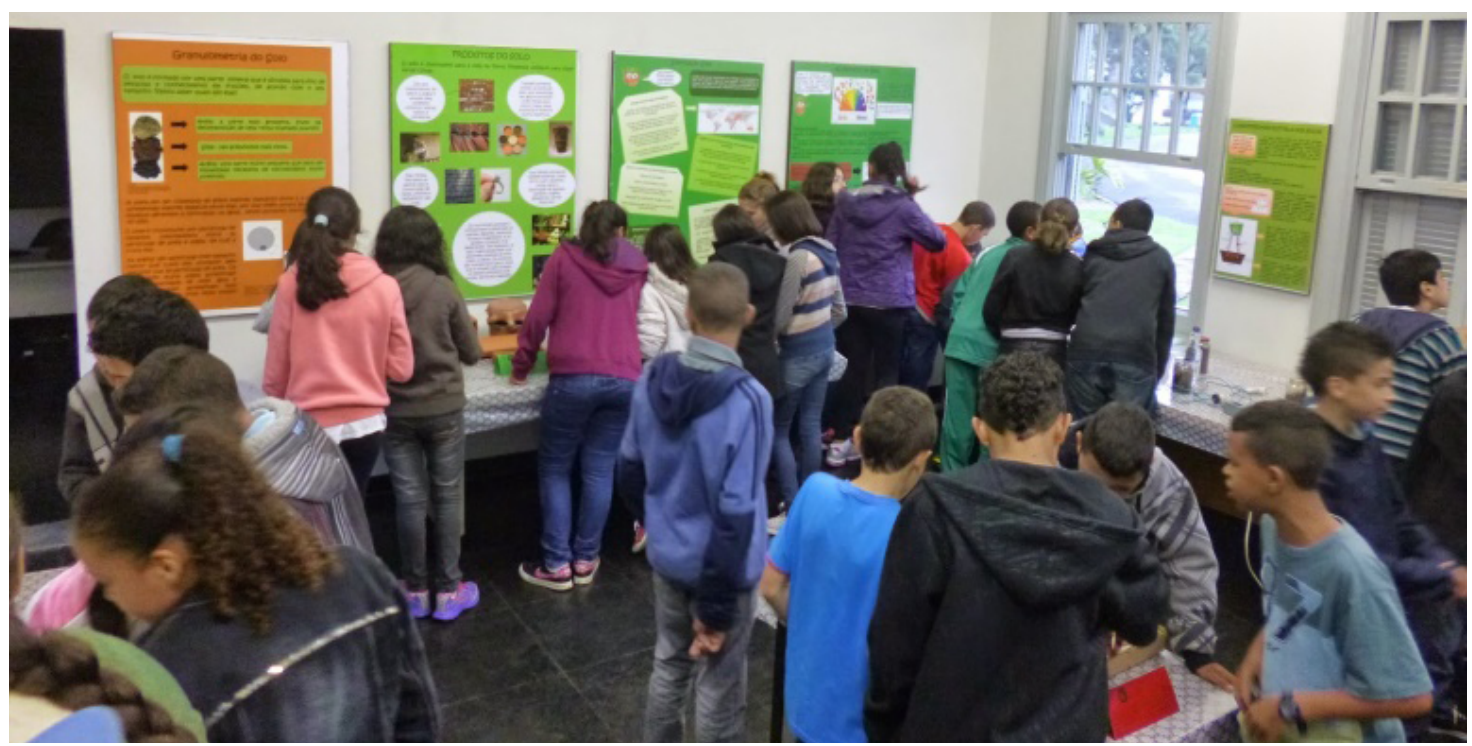

Figura 2 - Primeira escola visitante do Projeto Solo na Escola-Geografia-USP.

O ano de 2015, Ano Internacional do Solo, foi repleto de atividades realizadas por vários profissionais da educação em solos no Brasil e no Mundo. Teve pouca repercussão na mídia brasileira, como já esperávamos, pela falta de informação sobre o tema.

Em 2016 realizamos o VIII Simpósio Brasileiro de Educação em Solos, no Departamento de Geografia da USP entre os dias 7 e 10 de setembro, com o objetivo de contribuir para a formação de professores e estudantes paulistas e do Brasil como um todo, para que conheçam melhor o solo, a fim de utilizá-lo de forma sustentável e também preservá-lo. Esse evento é o mais importante do Brasil com a temática sobre educação em solos e teve a participação de aproximadamente trezentas pessoas ${ }^{1}$.

O Projeto Solo na Escola desenvolve atividades, exposições didáticas e experimentos relacionados aos seguintes temas:

- Formação do Solo: Exposição didática que mostra o início da formação do solo, desde a rocha sã até o solo com horizontes bem desenvolvidos (Figura 3).

- Perfil de Solo: Solo com os horizontes A, B, C e D ou rocha-mãe (Figura 4).

- Colorteca de Solos: Os solos possuem cores diferentes, que podem variar do negro ao branco, passando por amarelo, vermelho, alaranjado, esverdeado, azulado (Figura 5).
- Textura do Solo: Amostras contendo as frações do solo: areia, silte e argila (Figura 6).

- Granulometria do Solo: Frações granulométricas da areia presente no solo (Figura 7).

- Retenção de Água no Solo: Mostra o comportamento de diferentes solos ao reterem água (Figura 8).

- Filtro do Solo: O solo comporta-se como um filtro, pois retém as impurezas a ele adicionadas (Figura 9).

- Produtos do Solo: Diferentes objetos feitos com solo (Figura 10).

- Magnetismo do Solo: Alguns solos possuem propriedades magnéticas por apresentarem magnetita em sua composição, por isso são atraídos por um ímã (Figura 11).

- Microscopia do Solo: Por meio de microscópio óptico, podemos ver como o solo é constituído, em uma lâmina de solo (Figura 12).

- pH do Solo: Com materiais simples podemos estimar o pH do solo, como, por exemplo, utilizando vinagre e água sanitária (ou bicarbonato de sódio) (Figura 13).

- Solo como Condutor de Eletricidade: O solo conduz eletricidade para acender uma lâmpada (Figura 14).

- Solo como Produtor de Eletricidade: A energia que está no solo é capaz de acender um relógio digital (Figura 15). 


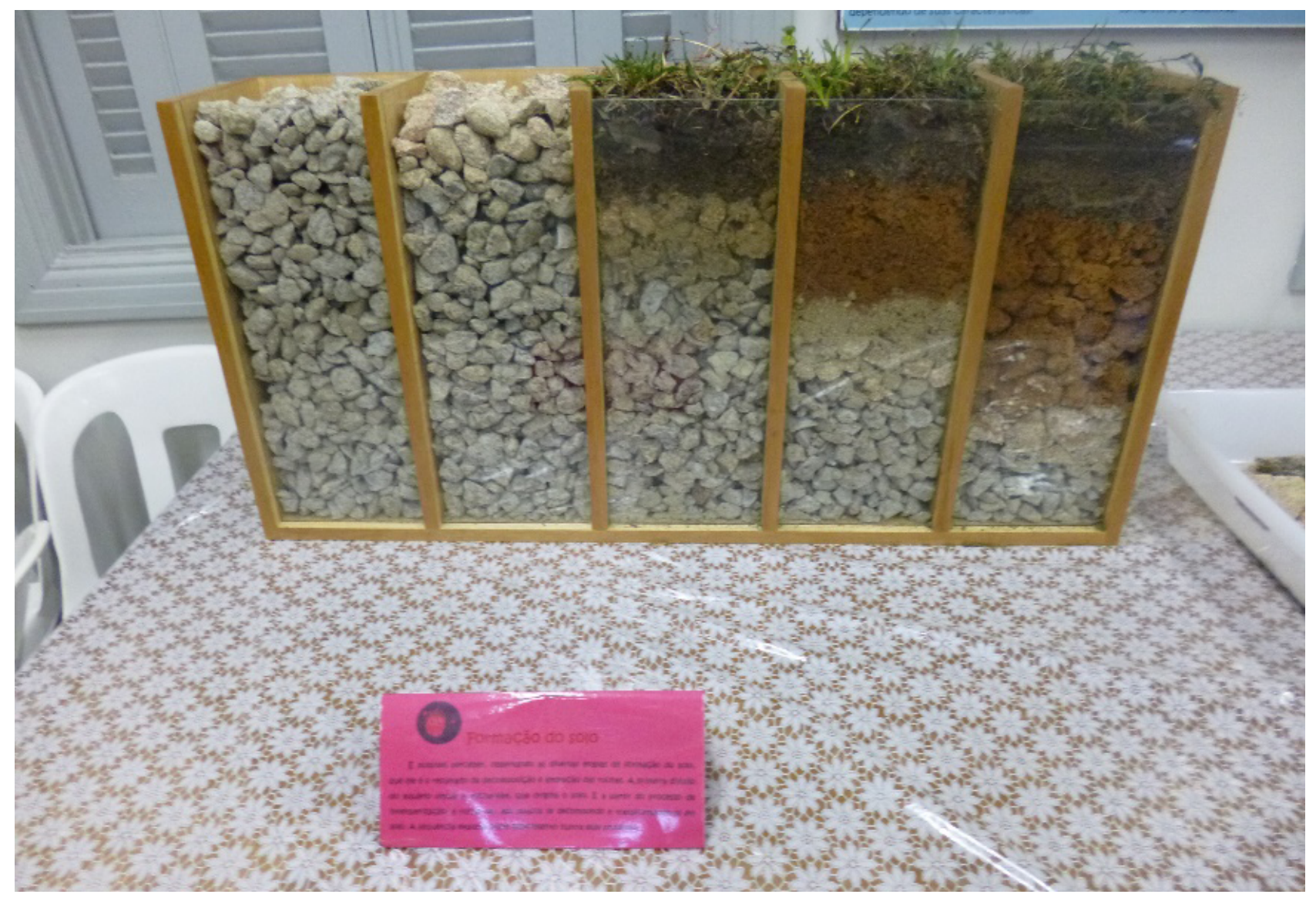

Figura 3 - Etapas da formação do solo.

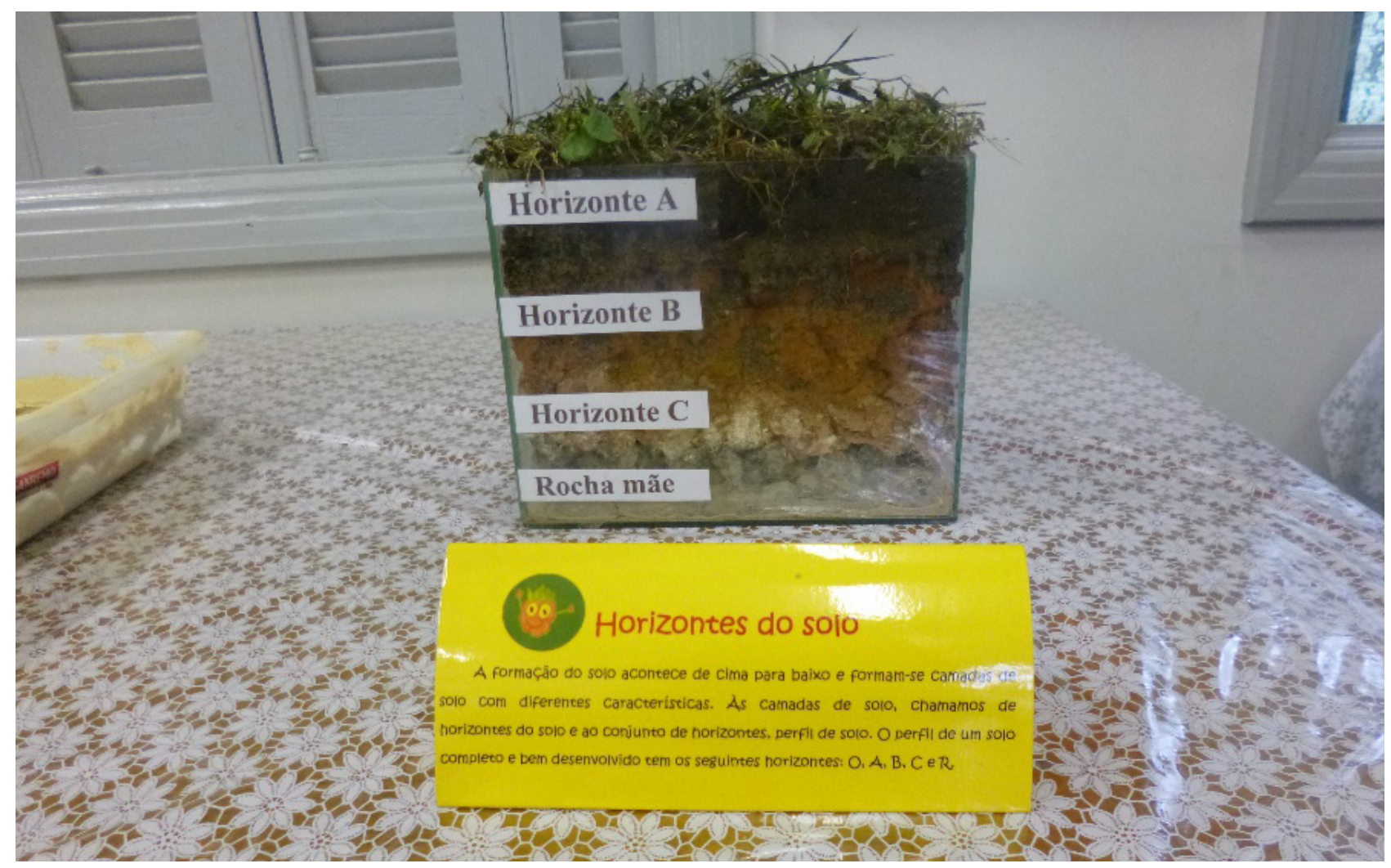

Figura 4 - Horizontes do solo. 


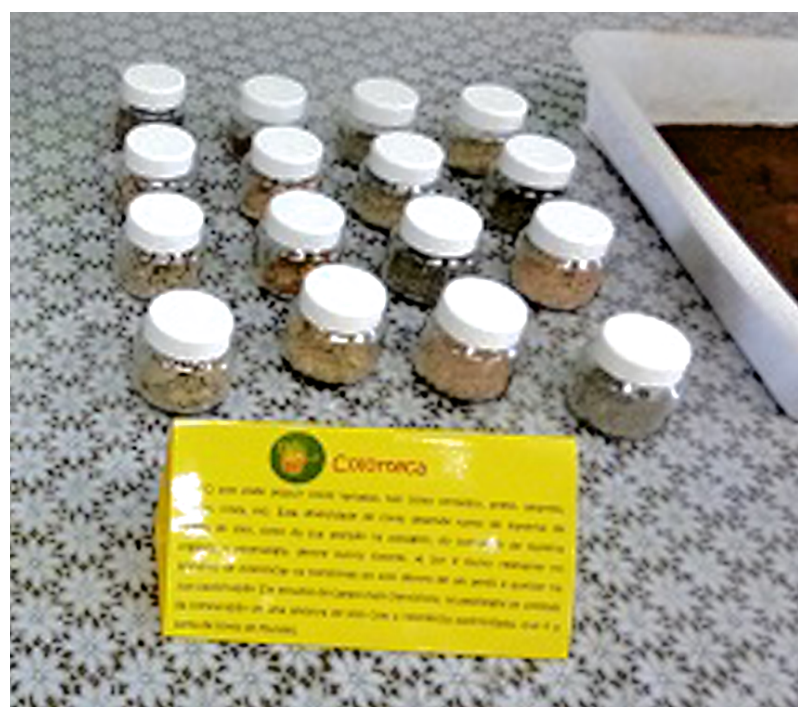

Figura 5 - Colorteca de solos.

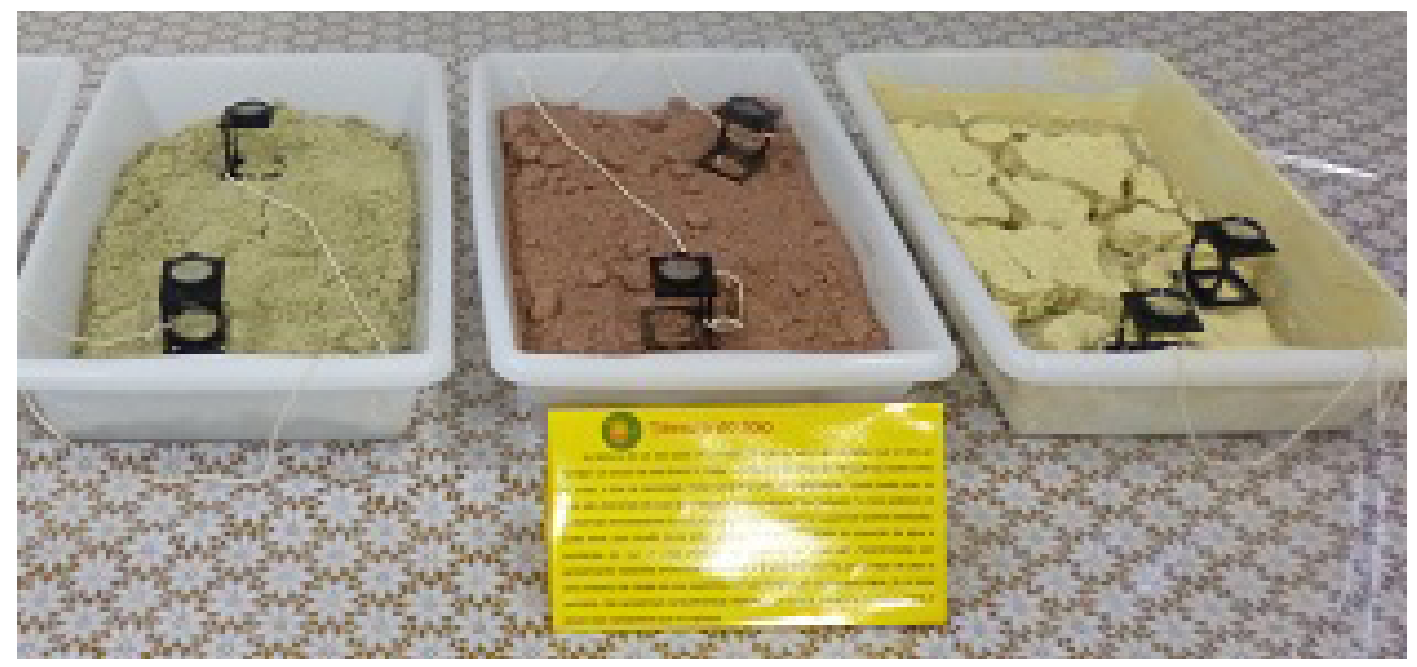

Figura 6 - Da esquerda para direita: areia, silte e argila presentes no solo.

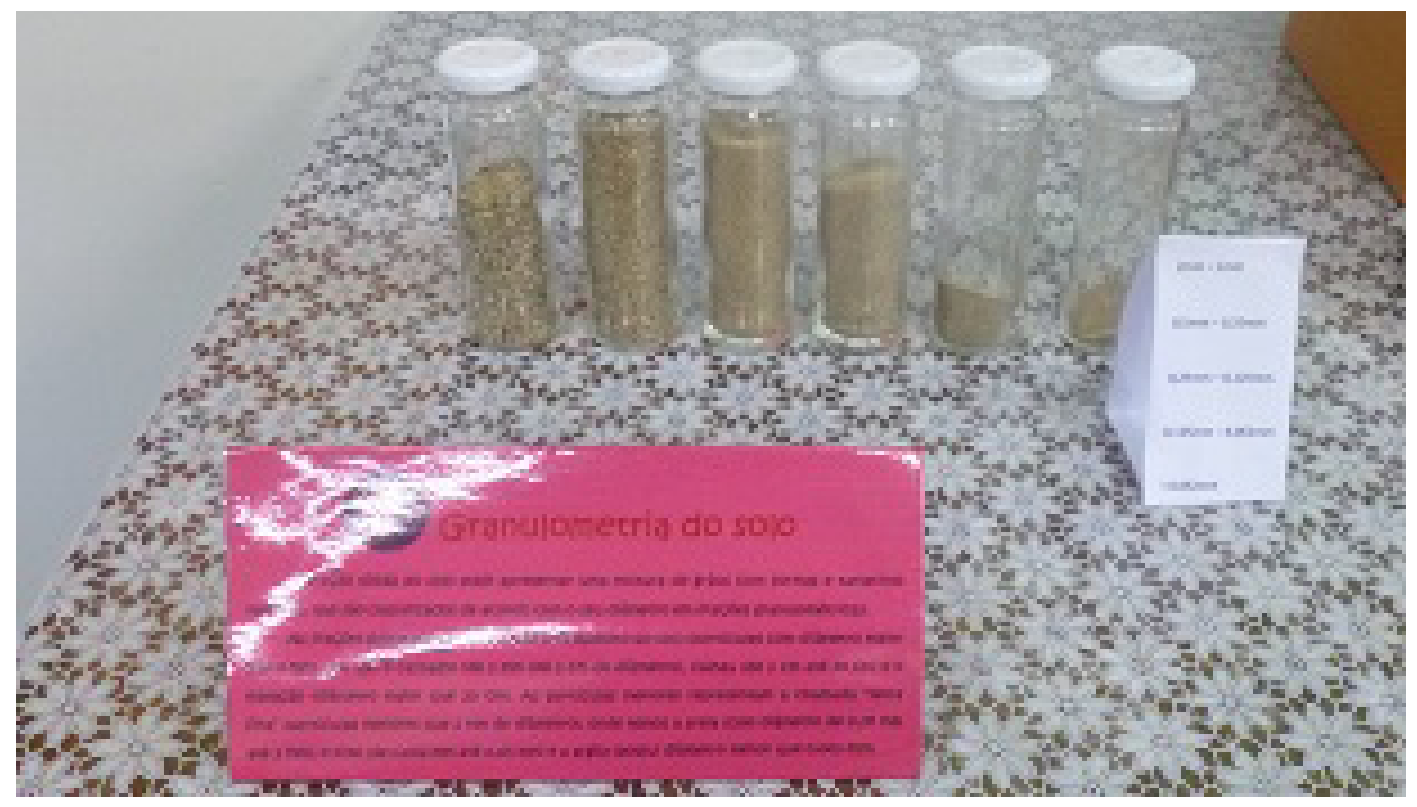

Figura 7 - Frações granulométricas da fração areia do solo. 


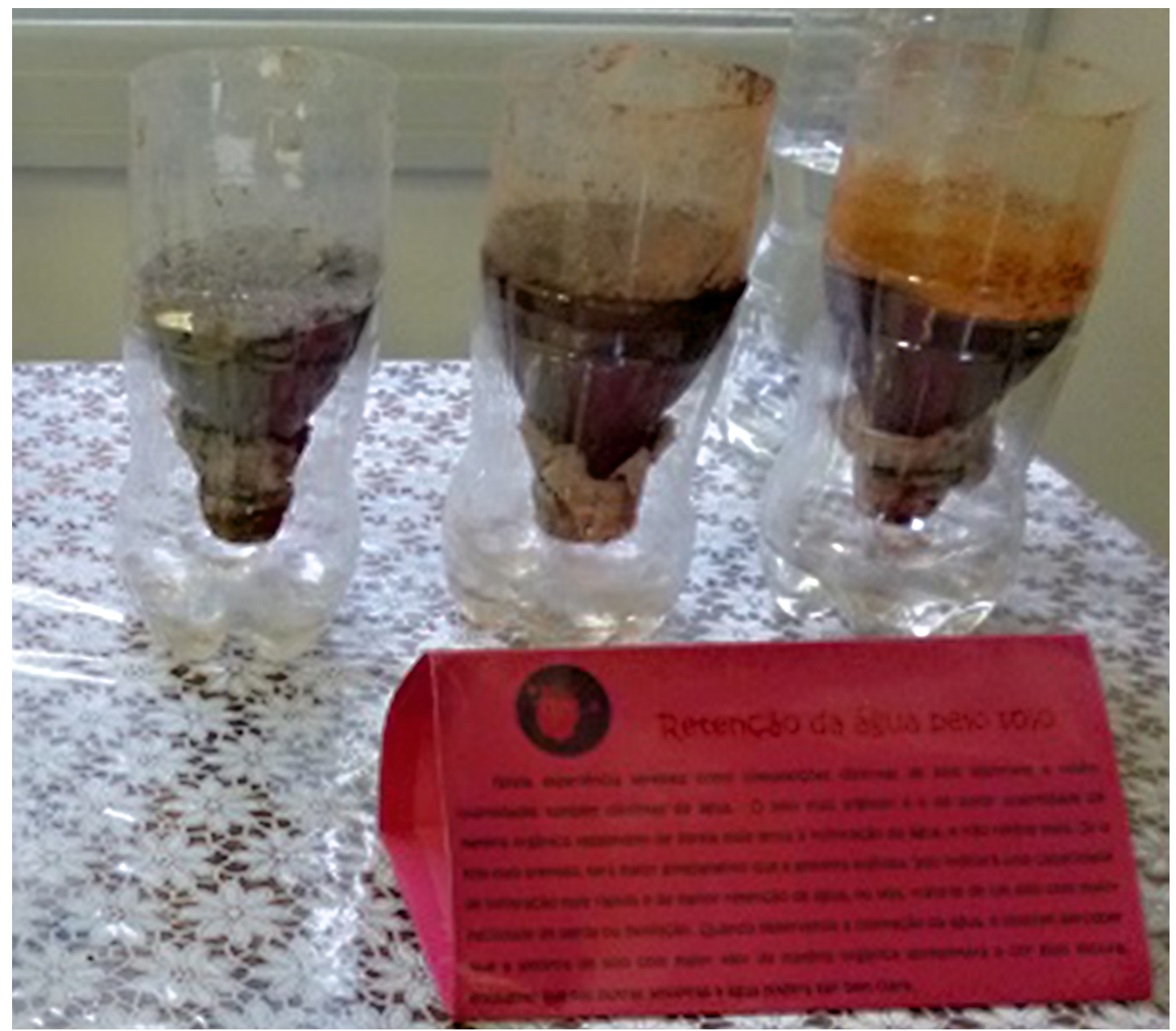

Figura 8 - Retenção da água pelo solo; da esquerda para a direita: solo arenoso, solo do jardim, solo argiloso.

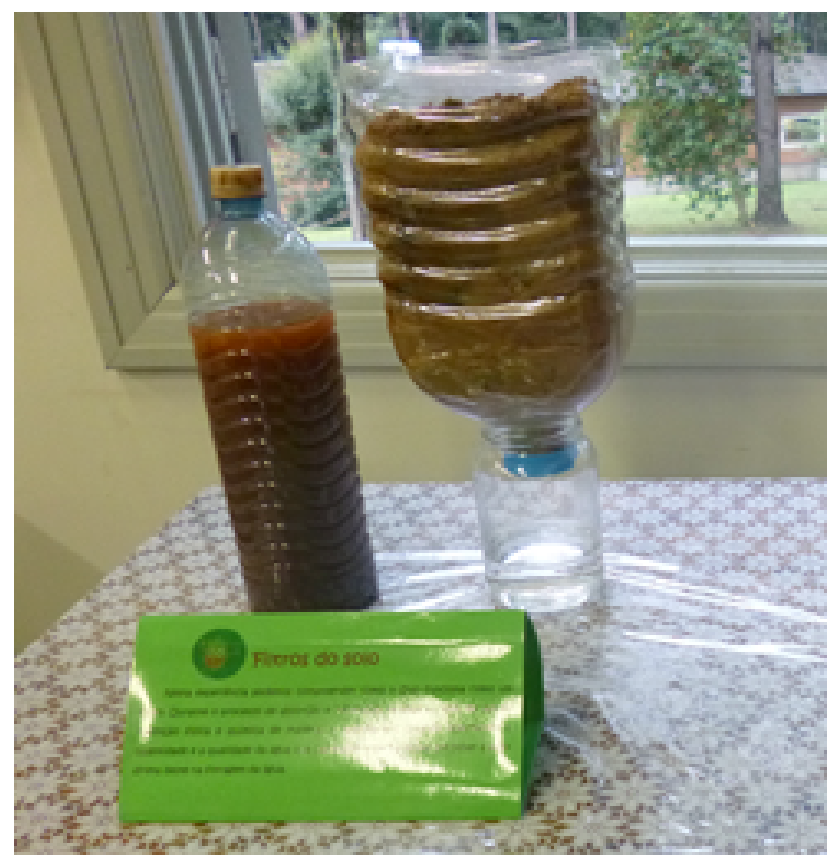

Figura 9 - O solo filtra e retém impurezas. Observar que a água que sai está límpida.

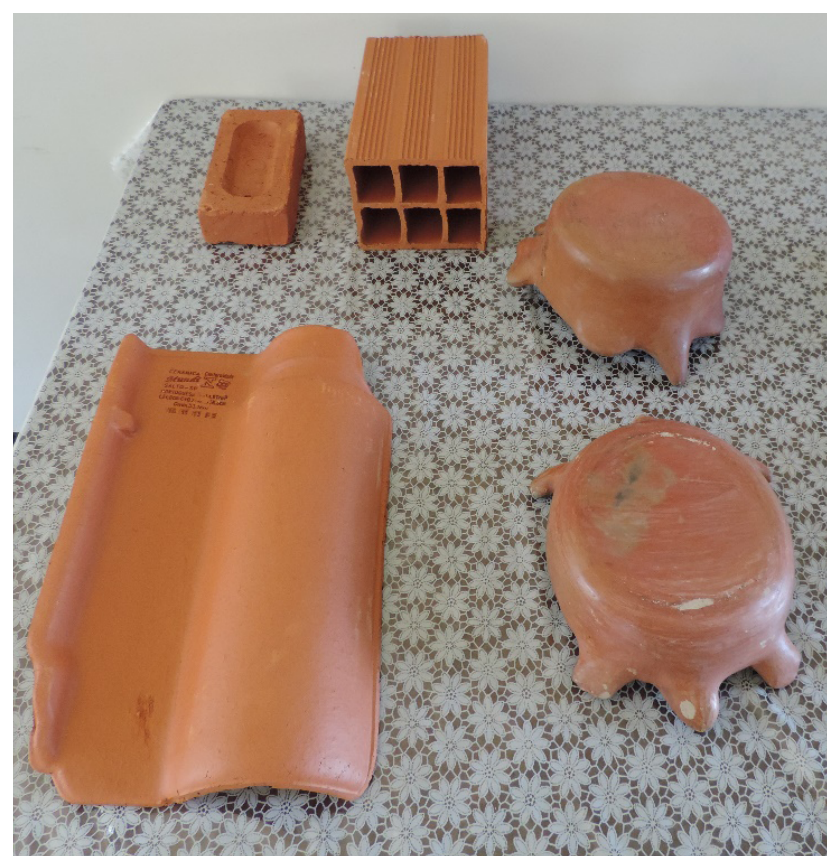

Figura 10 - Tijolos, telhas e cerâmica são feitos com a argila que vem do solo. 


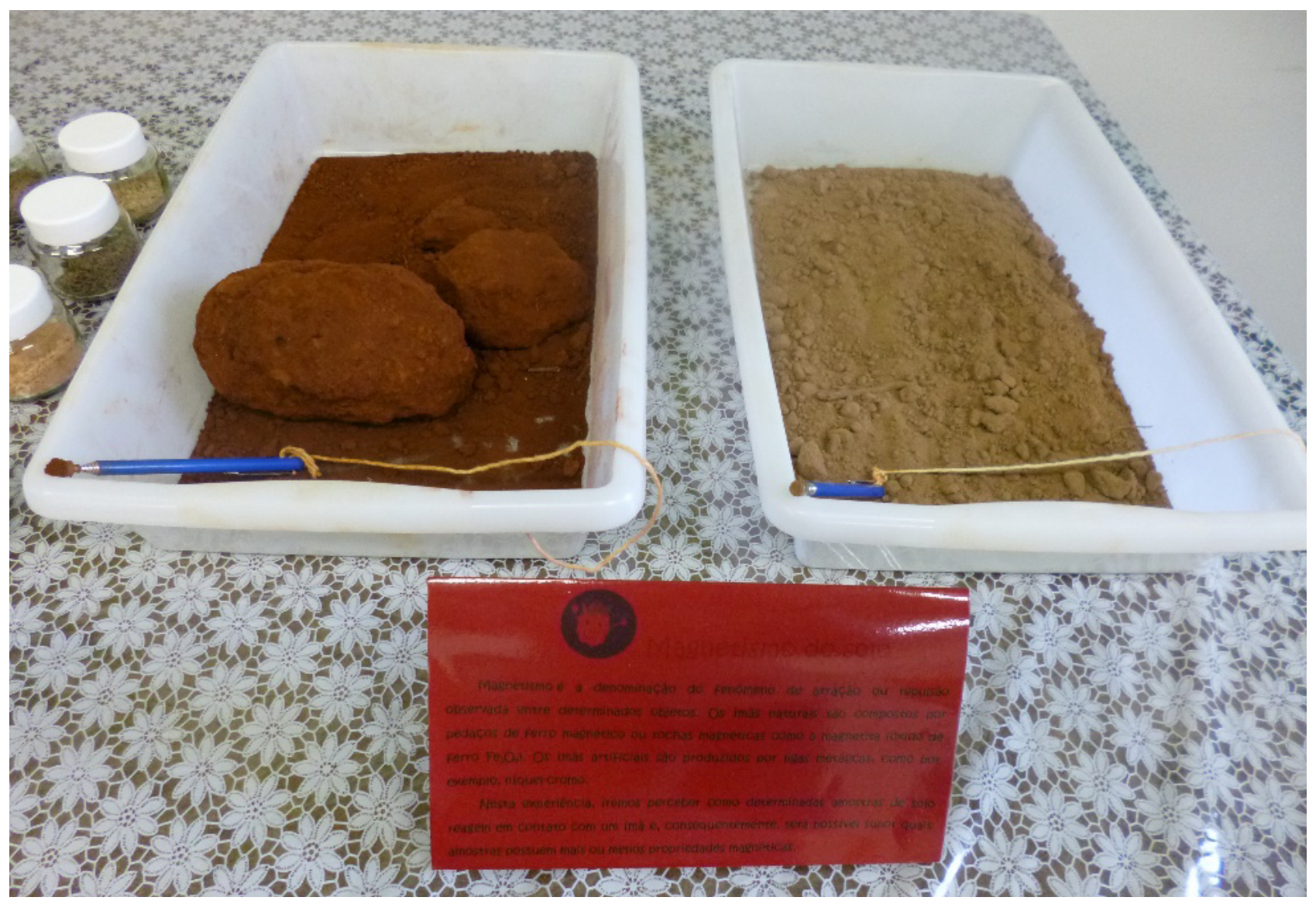

Figura 11 - Solo com magnetita é atraído por ímã (esq.).

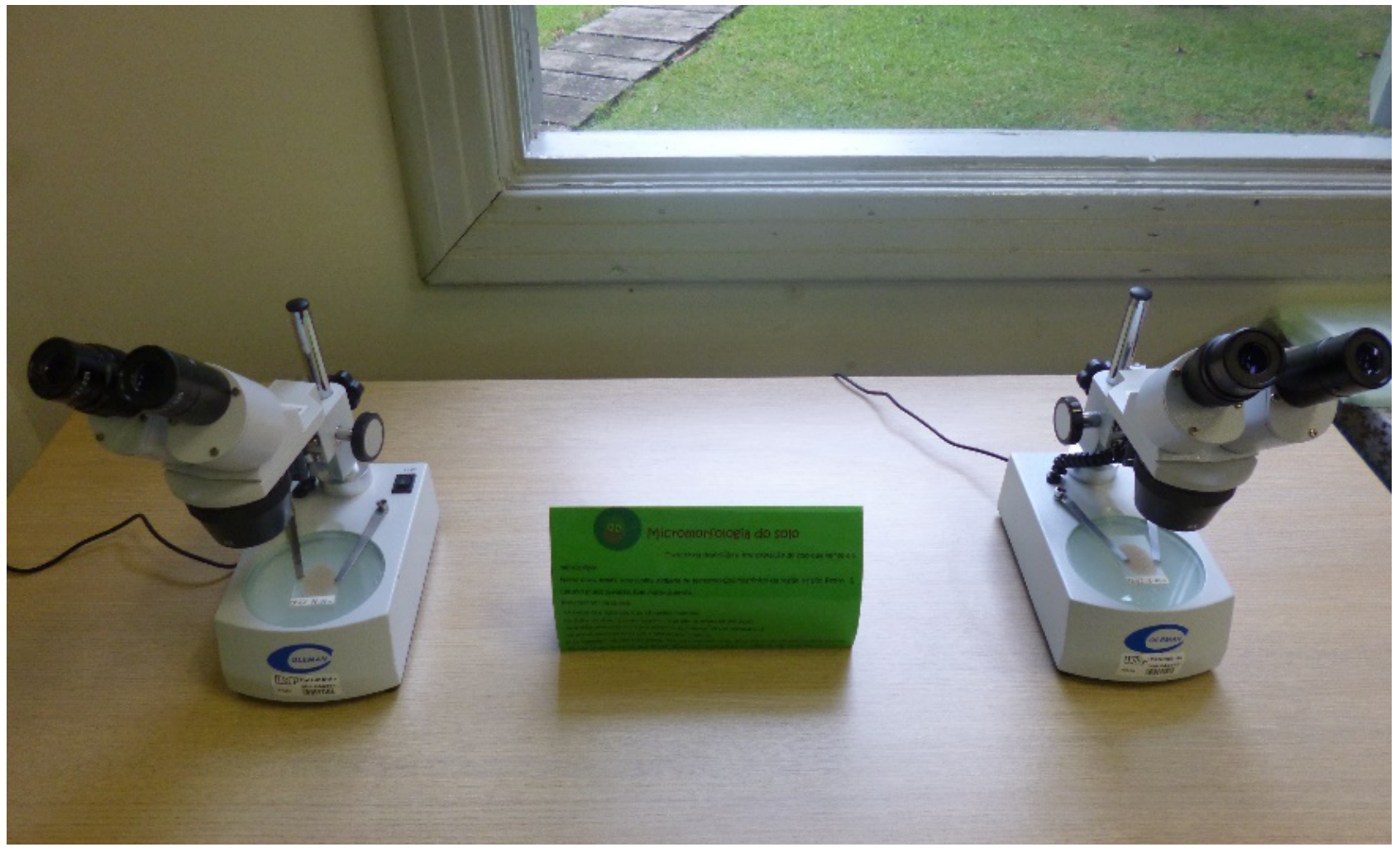

Figura 12 - Em lâminas de solos, vemos areia, silte, poros e argila. 


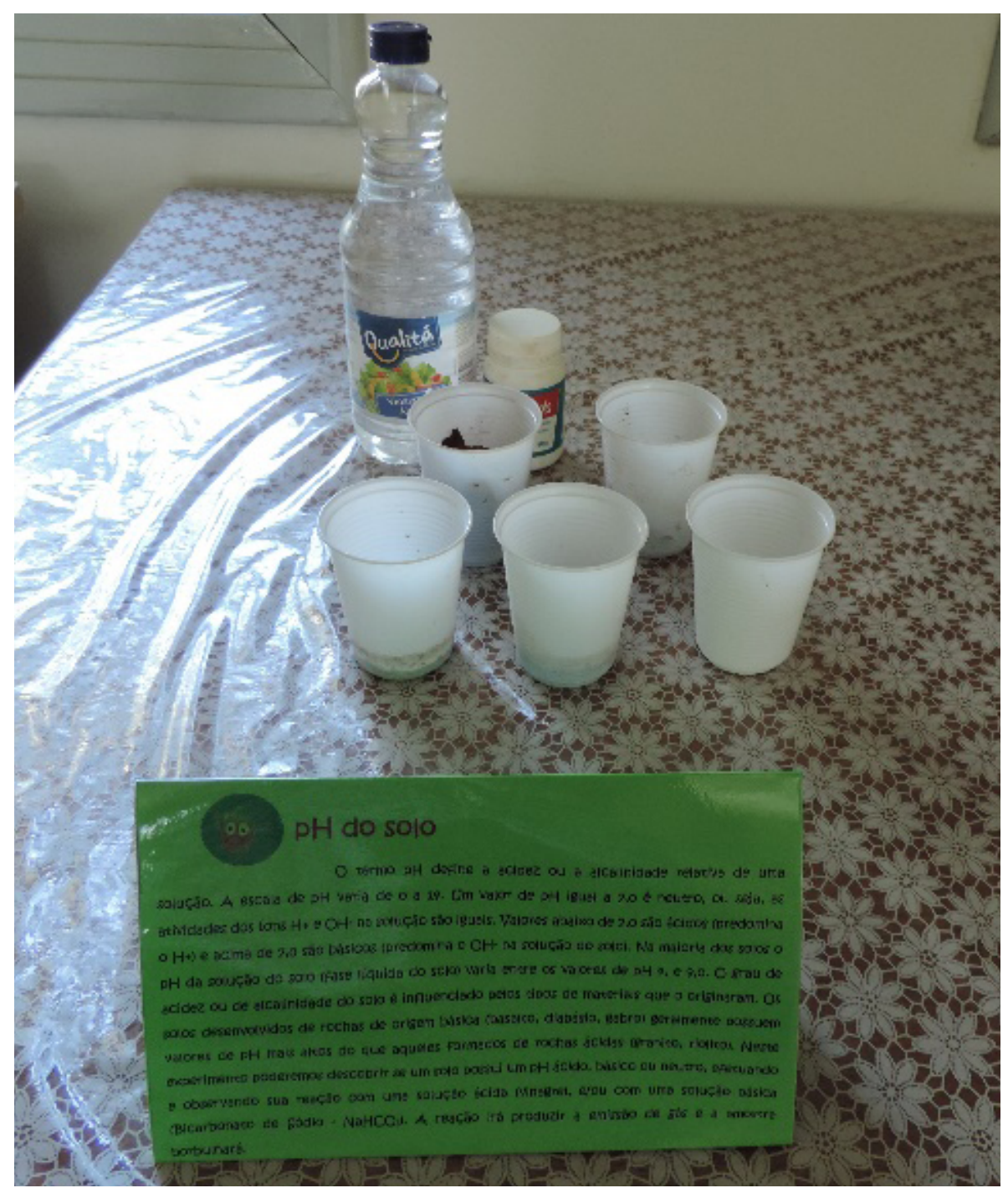

Figura 13 - Com um ácido e uma base podemos estimar o $\mathrm{pH}$ do solo.

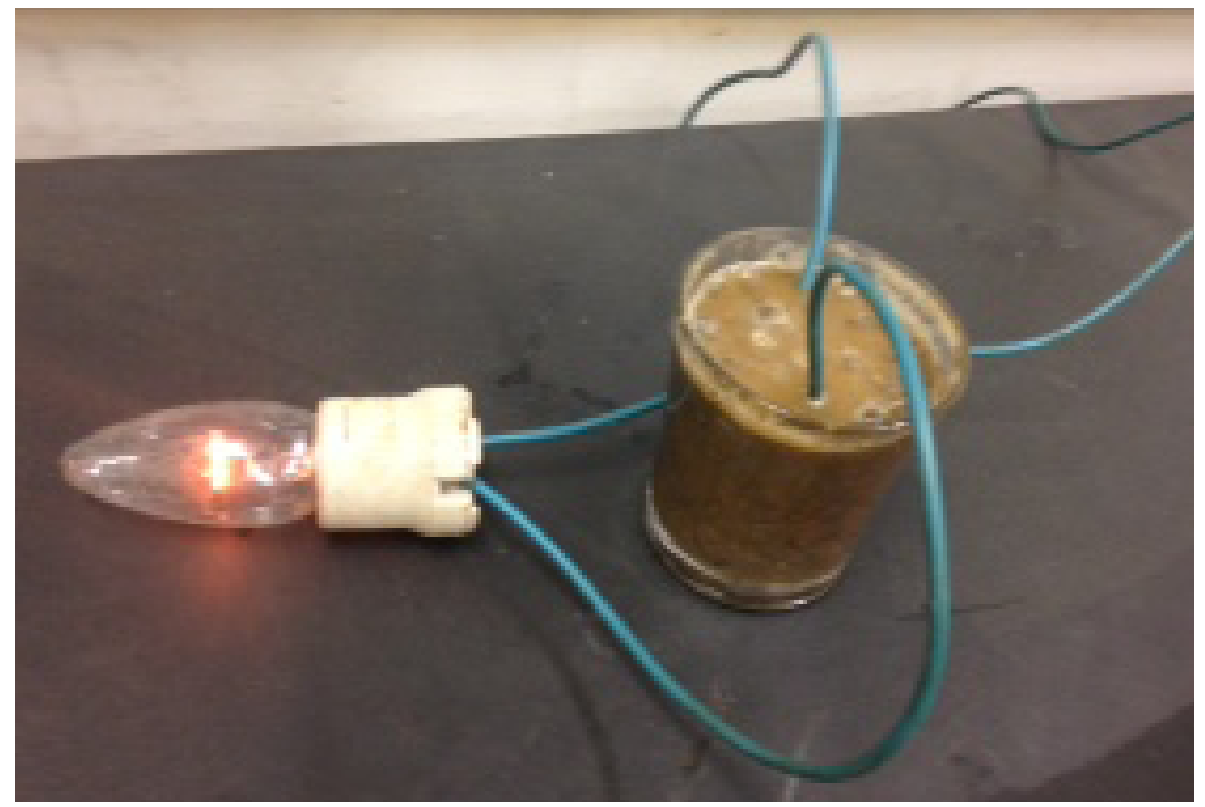

Figura 14 - O solo conduz eletricidade para acender uma lâmpada. 

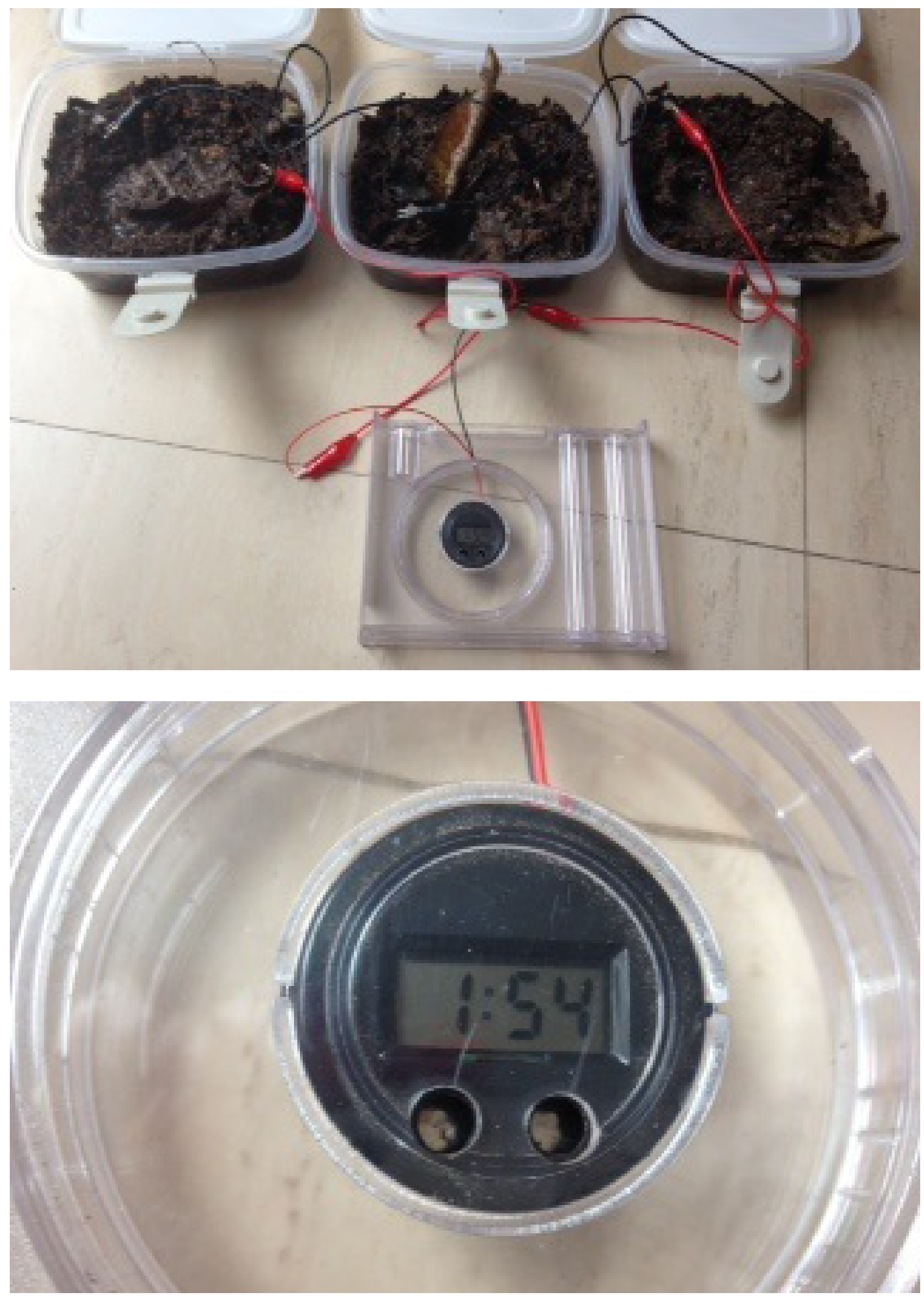

Figuras 15 e 16 - A energia presente no solo é capaz de acender um relógio digital. 
- Efeito "Splash": O solo com vegetação é mais protegido contra o impacto das gotas da chuva, enquanto o solo desprovido de vegetação é facilmente erodido (Figura 17).

- Erosão do Solo: O solo protegido com vegetação erode menos do que o solo com vegetação morta, e este erode menos do que um solo exposto (Figura 18).

- Amostras de Rochas, Minerais e Fósseis: Minerais e rochas que dão origem aos solos (Figura 19).

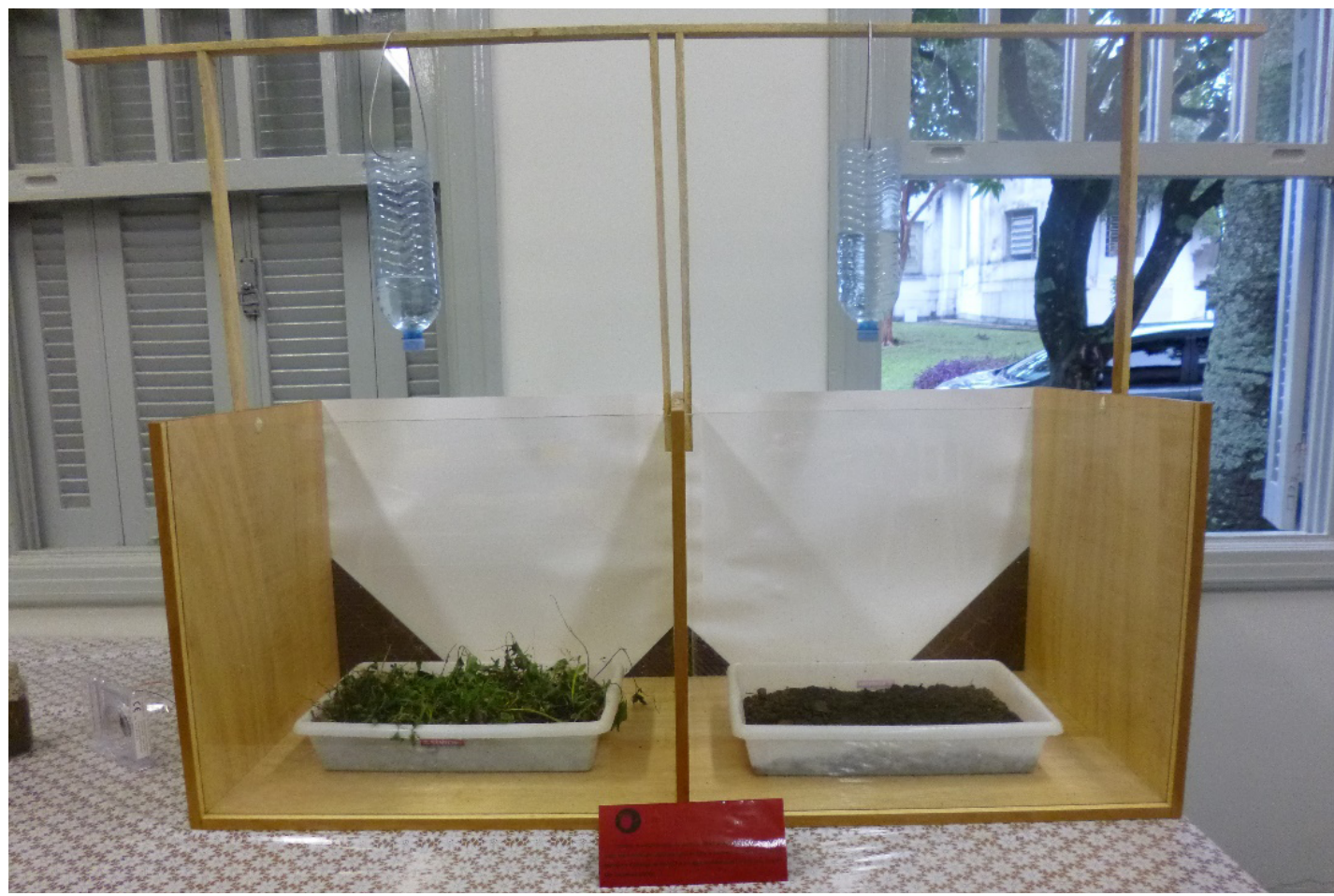

Figura 17 - O solo com vegetação é mais protegido do impacto das gotas da chuva.

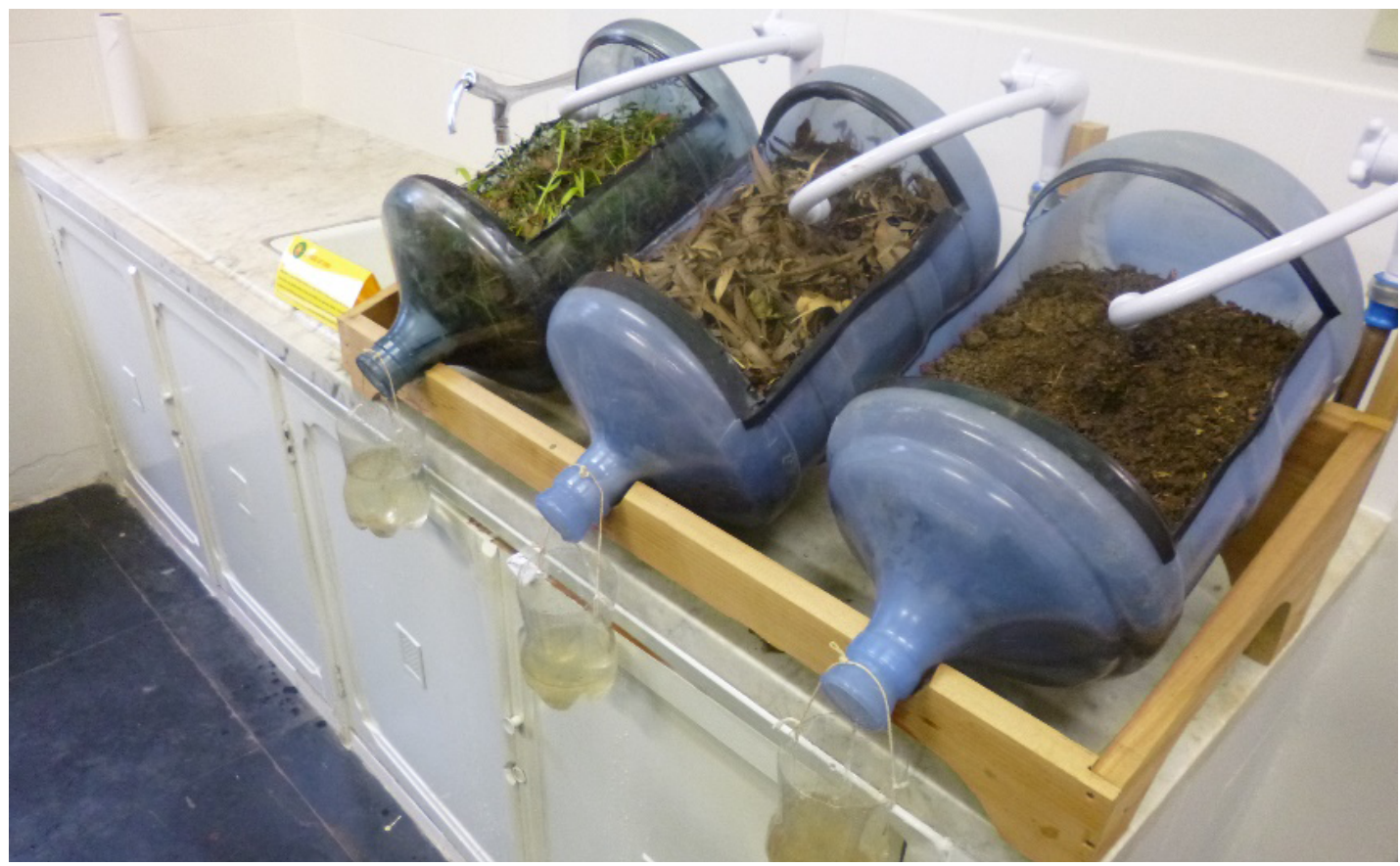

Figura 18 - O solo com vegetação viva é mais protegido contra erosão do que o solo com vegetação morta e do que o solo exposto. Da esquerda para direita, notar a cor da água que sai do experimento. 


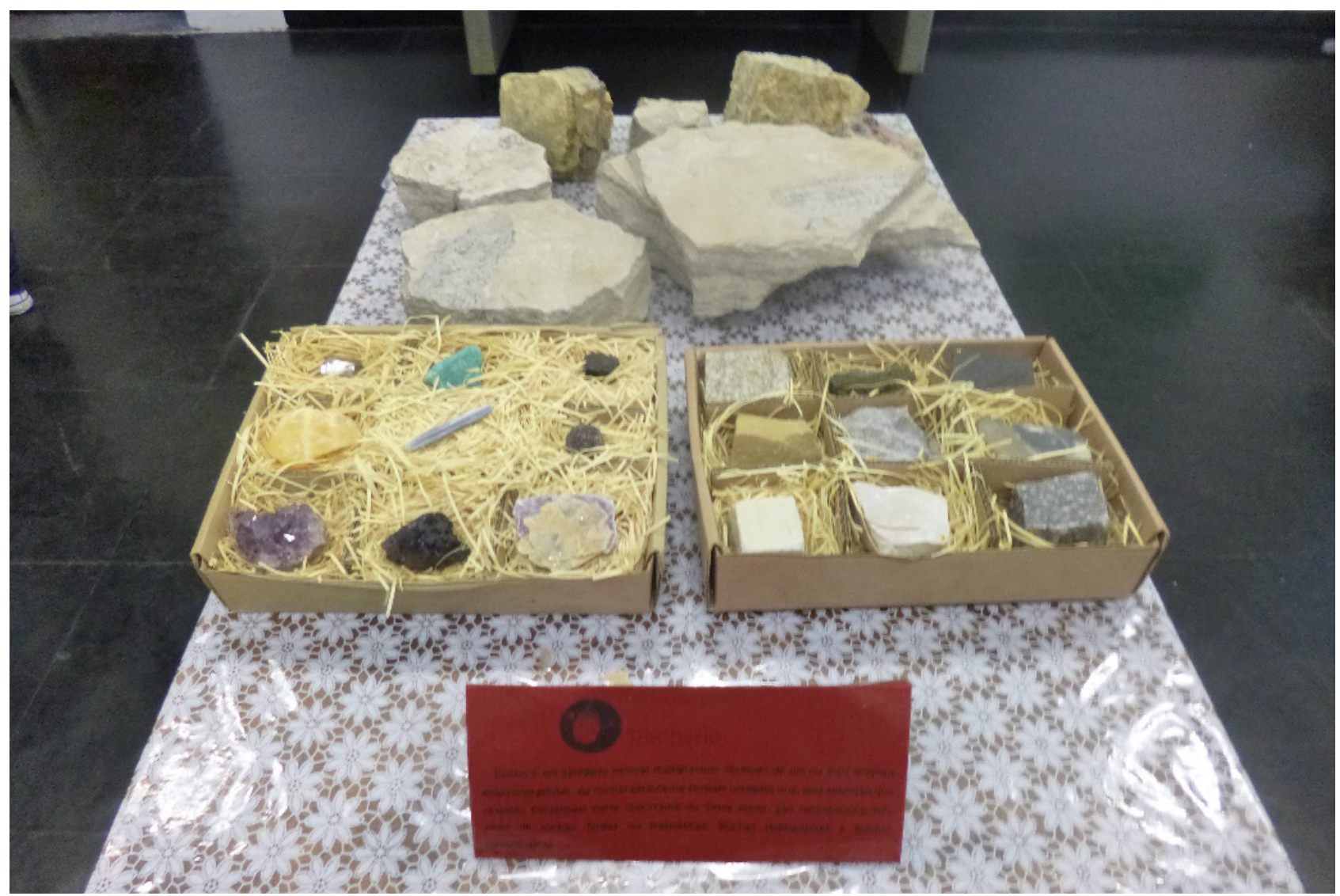

Figura 19 - Minerais e rochas são o material de origem do solo.

\section{Considerações Finais}

Atualmente os bolsistas desenvolvem materiais didáticos para professores e os disponibilizam no $b \log$ do projeto $^{2}$, além de divulgarem informações importantes relacionadas ao solo na nossa página do Facebook ${ }^{3}$. O projeto já recebeu mais de $10 \mathrm{mil}$ pessoas até o momento.

\section{Notas}

1 A página web do VIII Simpósio Brasileiro de Educação em Solos é: http://viiisbes.fflch.usp.br/.

2 A página web do blog do Projeto Solo na Escola-Geografia-USP é: http://solonaescolageografiausp.blogspot.com.br/.
3 A página web do Facebook do Projeto Solo na EscolaGeografia-USPé: https://www.facebook.com/solonaescolageografiausp/.

\section{Referências Bibliográficas}

MUGGLER, C. C; SOBRINHO, F. de A. A. P. \& MACHADO, V. A. "Educação em Solos: Princípios, Teoria e Métodos". Revista Brasileira de Ciência do Solo, vol. 30, n. 4, pp. 733-740, 2006.

OLIVEIRA, D. de. O Solo sob Nossos Pés. São Paulo: Atual, 2010.

"O Conceito de Solo sob o Olhar de Crianças do Ensino Fundamental em Escolas de São Paulo-SP". Ciência e Natura, Santa Maria, vol. 36, Ed. Especial, pp. 210-214, 2014.

Publicado em 22/12/2017. 